\title{
Effect of leading-edge geometry on the aerodynamics and heat transfer in the stagnation region of uncooled turbine blades
}

\author{
A AROCKIA FENIL ${ }^{1,2}$ and M SIVAPRAGASAM ${ }^{1, *}{ }^{\mathbb{B}}$ \\ ${ }^{1}$ Department of Automotive and Aeronautical Engineering, Faculty of Engineering and Technology, M S \\ Ramaiah University of Applied Sciences, Bengaluru 560 058, India \\ ${ }^{2}$ Present Address: Society for Innovation and Development, Interdisciplinary Centre for Energy Research, \\ Indian Institute of Science, Bengaluru 560 012, India \\ e-mail: sivapragasam.aae.et@msruas.ac.in
}

MS received 31 July 2017; revised 12 February 2018; accepted 29 May 2018; published online 5 October 2018

\begin{abstract}
The flow in the leading-edge stagnation region of uncooled turbine aerofoils is studied. The stagnation region is modelled based on the Hiemenz flow solution, following Holley and Langston (J. Turbomach. 130: 021001, 2008). These results are applied to the JT9D turbine blade and confirmed by computations. It is also shown that the heat transfer at the stagnation point is bounded by the Hiemenz flow and plane stagnation-point potential flow heat transfer solutions. The computations are further extended for a range of Reynolds numbers and freestream turbulence intensities. It is seen that for a wide range of these parameters considered in the present study and data collected from published literature, a majority of the data points are within these bounds. The leading-edge geometry of the JT9D turbine blade is modified with elliptical geometries. Blunter-leading-edge geometries have lower values of heat transfer at the stagnation region; however, their blade profile loss coefficients are higher. The off-design performance characteristics of the turbine blades are also computed. The results presented in this paper will be useful in designing leading-edge geometries for reduced heat transfer in the stagnation region of uncooled turbine blades.
\end{abstract}

Keywords. Gas turbine; turbine cooling; turbine leading edge; similarity solution; profile loss coefficient.

\section{Introduction}

The continued demand to improve the efficiency of gas turbine engines for both aircraft propulsion and land-based power generation necessitates higher turbine inlet temperatures. The thermal efficiency and specific power output of a gas turbine engine increase with an increase in turbine inlet temperature. Present day turbines operate at temperatures substantially higher than the blade metal melting temperature. This is made possible by advances in material technologies, coating techniques and sophisticated blade cooling arrangements. An improved understanding of turbine blade heat transfer phenomena and development of predictive capabilities are essential in the design of efficient cooling strategies. Excellent reviews of turbine blade heat transfer and cooling techniques can be found in [1-4].

The leading edge of the turbine vane or blade is the most critical region as it has to withstand the highest pressures and temperatures of the hot gas path. In particular, since the first-stage nozzle vane at the exit of combustor is exposed to the highest temperature, an elaborate cooling arrangement involving a fairly large amount of compressor bleed

*For correspondence air is employed. Further, the initial boundary layer development on the leading edge has a significant effect on the flow over the rest of the blade. It thus becomes imperative to gain a detailed knowledge of the aerodynamics and heat transfer at the leading-edge region. Most advanced gas turbines have intricate turbine blade cooling arrangements. However, many gas turbine systems have uncooled turbine blades. For example, small gas turbine engines like HAL's PTAE-7 and GTSU-110 have uncooled turbines. The power turbines of land-based gas turbines like Siemens SGT-700 and General Electric LM series are also uncooled. A couple of uncooled turbine blades available in the authors' laboratory is shown in figure 1 .

Within the leading-edge region of the turbine blade, the highest heat transfer rate normally occurs in the stagnation region. In the past, the stagnation region has been modelled as a circular cylinder in cross-flow. In this connection, the early theoretical work of Frössling [5] deserves mention. The temperature distribution in a laminar boundary layer about a body of arbitrary shape was obtained by solving the boundary layer equations. The results were presented in terms of the parameter, $N u / \sqrt{ } R e$, which now bears his name. Here, $\mathrm{Nu}$ is the Nusselt number and $R e$ the Reynolds number. However, this theoretical solution does not 


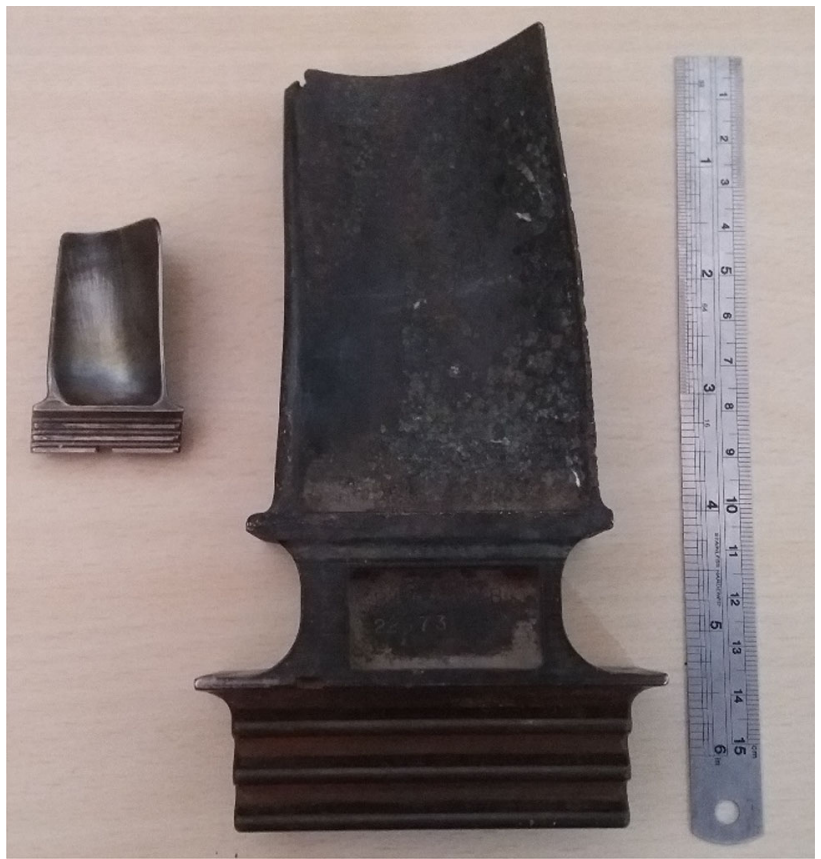

Figure 1. Uncooled turbine blades. (Photograph by MS.)

account for the effects of freestream turbulence on the laminar boundary layer, and agreement with experimental data is good only when the freestream turbulence intensity, $T u$, is low. At higher values of $T u$, the heat transfer rate is significantly higher. The systematic dependence of the heat transfer rate in the stagnation region on $T u$ is now well known and the Frössling solution has been used as a reference to report this dependence.

An interesting approach of modelling the turbine blade leading-edge stagnation region based on the Hiemenz flow solution was proposed by Holley and Langston [6]. A similarity solution of the flow field is readily obtained, and is one of the few exact solutions of the Navier-Stokes equations [7]. The Hiemenz solution is uniquely characterized by a parameter $a$, which is defined as $a=U_{\infty} / L$, where $U_{\infty}$ is the freestream velocity and $L$ is a distance measured along the stagnation streamline. In general, a geometry-dependent coefficient is associated with the definition of $a$, but can be absorbed in $L$. To some scale $L$, the Hiemenz solution can be applied in the stagnation region of turbine blades.

Further, the heat transfer solution in the stagnation region can be obtained for the Hiemenz flow and its inviscid counterpart, the plane stagnation-point potential flow; it was demonstrated in [6] that these solutions provide the lower and upper bounds, respectively, on the stagnationpoint heat transfer for five different turbine aerofoils. These aerofoils are representative of a wide range of turbine vane and rotor blade geometries. It was also asserted that once $L$ is known, the stagnation-point heat transfer can be bracketed by these bounding values. The leading-edge geometry can be redesigned, if so desired, so that the heat transfer can be reduced by altering $L$. Clearly, the problem at hand is the evaluation of the scale $L$, with which the flow field and the heat transfer near the leading-edge stagnation region of turbine blades can be reckoned at once.

The scale $L$ was evaluated in [6] for $R e=5.9 \times 10^{5}$ and $T u=1 \%$. It was also suggested in [6] that the stagnationpoint heat transfer can be reduced by choosing a higher value of $L$ without any further elaboration. The present study pertains to the computational evaluation of the scale $L$ by extending the parameter range of $R e$ and $T u$. It is also shown in the present paper that by modifying the circular leading edge with elliptical ones the stagnation-point heat transfer can be reduced.

In the light of this discussion, the main objectives of this study are two-fold. Firstly, to apply the Hiemenz flow and plane stagnation-point potential flow solutions to turbine blade leading-edge stagnation region and show that these solutions bound the stagnation-point heat transfer. Secondly, to modify the turbine blade leading-edge geometry in a systematic manner and demonstrate that the stagnationpoint heat transfer can be reduced.

This paper is organized as follows. In section 2 the stagnation-point flow solution is briefly reviewed, which leads us to reckon the importance of the scaling parameter $L$. The computational procedure is detailed in section 3, and the results are presented in section 4 demonstrating the usefulness of the scaling parameter. The variation of this scaling parameter and heat transfer at the leading-edge stagnation region is presented, first for different values of Reynolds number and freestream turbulence intensities, and then for various leading-edge geometries. The off-design aerodynamic performance characteristics of the modified leading edges are also presented. Finally a summary is provided and conclusions are drawn in section 5.

\section{Stagnation-point flow solution}

In this section we briefly present the stagnation-point flow solution for viscous and potential flows, while referring to Schlichting [7] for details. The following exposition is summarized from Langston and Holley [8]. The boundary layer displacement thickness, $\delta^{*}$, in this flow field is

$$
\delta^{*}=\int_{0}^{\infty}\left(1-\frac{u}{U_{\infty}}\right) d y=0.648 \frac{L}{\sqrt{R e}} .
$$

This is the amount by which the inviscid flow is displaced due to viscous effects. $R e$ is the Reynolds number based on the freestream velocity $U_{\infty}$ and the length scale $L$.

The skin friction coefficient, $C_{f}$, is given by

$$
C_{f}=\frac{\tau_{w}}{1 / 2 \rho U_{\infty}^{2}}=\frac{2.4652}{\sqrt{\operatorname{Re}}} \frac{x}{L}
$$


where $\tau_{w}$ is the wall shear stress.

The pressure distribution in the stagnation region, in both inviscid and viscous flows, is given by

$$
C_{p}=\frac{p-p_{\infty}}{1 / 2 \rho U_{\infty}^{2}}=1-\left(\frac{u}{U_{\infty}}\right)^{2}=1-\left(\frac{x}{L}\right)^{2} .
$$

A similarity solution for the temperature distribution, due to Squire [9, 10], can also be obtained by neglecting the viscous dissipation function in the energy equation. This solution eventually leads to

$$
\text { St } \operatorname{Pr} \sqrt{\operatorname{Re} L} \approx 0.57 \operatorname{Pr}^{0.393}
$$

where $S t$ is the Stanton number and $\operatorname{Pr}$ is the Prandtl number. St and $\mathrm{Pr}$ are defined as follows:

$$
\begin{gathered}
S t=\frac{q}{\left(T_{w}-T_{\infty}\right) \rho U_{\infty} c_{p}}, \\
\operatorname{Pr}=\frac{v}{\alpha_{t}}
\end{gathered}
$$

where $q$ is the heat flux, $c_{p}$ is the specific heat at constant pressure, $\alpha_{t}$ is the thermal diffusivity, $v$ is the kinematic viscosity, and $T_{\infty}$ and $T_{w}$ are the freestream and wall temperatures, respectively. It is worth noting that the solution Eq. (4) does not depend on $x$, which implies that the heat transfer coefficient also would not depend on $x$; thereby, the constant temperature and constant heat flux solutions are identical. Thus $S t$ will be uniform along $x$, whether the surface is maintained at constant temperature or with constant heat flux [11].

In the potential flow limit, a solution similar to Eq. (4) can be obtained as [6]

$$
\text { St } \operatorname{Pr} \sqrt{\operatorname{Re} L}=\sqrt{\frac{2 \operatorname{Pr}}{\pi}} \text {. }
$$

This result is to be interpreted as the heat transfer solution in the low $\operatorname{Pr}$ limit, where the thermal boundary layer is much thicker than the momentum boundary layer [7]. To summarize the developments so far, in Hiemenz flow, $C_{f}$ varies linearly with $x$, and is zero at the stagnation point, $C_{p}$ variation is parabolic in $x$ and $S t$ is uniform along $x$. The momentum boundary layer is absent in potential flow, and the thermal boundary layer is thinner than the Hiemenz flow. This leads to the important conclusion that for equivalent values of $T_{\infty}$ and $T_{w}$, the heat flux is lower in Hiemenz flow than in the potential flow.

At this stage of our discussion it is prudent to combine Eqs. (4) and (7) to yield

$$
0.57 \operatorname{Pr}^{-0.107} \leq S t \sqrt{\operatorname{Pr} \operatorname{Re} L} \leq \sqrt{\frac{2}{\pi}}
$$

which is accurate to within $1 \%$ for $0.2<\operatorname{Pr}<2$. In terms of the Frössling number, Eq. (8) can be written as

$$
1.11 \operatorname{Pr}^{0.393} \leq F r \leq 1.56 \sqrt{P r}
$$

where the Frössling number $F r=N u_{D} / \sqrt{ } \operatorname{Re}_{D}$, and $D$ is the equivalent cylinder diameter, which is related to $L$ as $\pi D=12 L[6]$.

It was shown in [6] that the stagnation-point heat transfer results of five different turbine blades were bounded by the values given by Eq. (8) or (9), with the lower limit on the left-hand side corresponding to the Hiemenz flow solution, and the upper limit corresponding to the potential flow solution. In section 4.2 , we will see the validity and utility of the model in Eq. (8) or (9).

We now proceed to compute the flow field over the turbine blades; but before that, in the passing, we shall briefly mention two points. Firstly, in several flow situations, regions of high shear are usually accompanied by regions of high heat and mass transfer since they are governed by similar transport processes and equations. This well-known analogy, due to Reynolds, has been successfully applied to many heat and mass transfer problems. A notable exception is the stagnation region, where the skin friction is nearly zero but the heat transfer is high.

Secondly, it is interesting to note that the solutions of the flow equations of Hiemenz flow are non-unique. The multiplicity of solutions of the Navier-Stokes equations is not surprising considering their non-linear nature. Indeed, a dual solution was obtained in $[12,13]$. The other solution, for example, had a displacement thickness that is considerably larger than in Eq. (1), but does not commonly occur in practice. We mention this fact here out of sheer mathematical curiosity, and it will have no bearing on the results presented in this paper.

\section{Computational procedure and validation}

In this section the procedure for numerically computing the flow field over the turbine blade is discussed. The purpose of the computations was manifold, namely:

(i) to reliably compute the flow over turbine blades, including the leading-edge region,

(ii) to accurately evaluate $L$ for different values of $R e$ and $T u$, and for different leading-edge geometries,

(iii) to assess the validity of Eq. (8) and complement it and

(iv) to evaluate the off-design performance of the turbine blades.

To achieve these aims, a careful numerical study has been conducted.

The Pratt and Whitney JT9D first-stage turbine blade was chosen for the computations, since the geometrical details of this blade and experimental and computational results were available [6, 14, 15]. The experiments had been conducted in a low-speed plane turbine cascade wind 


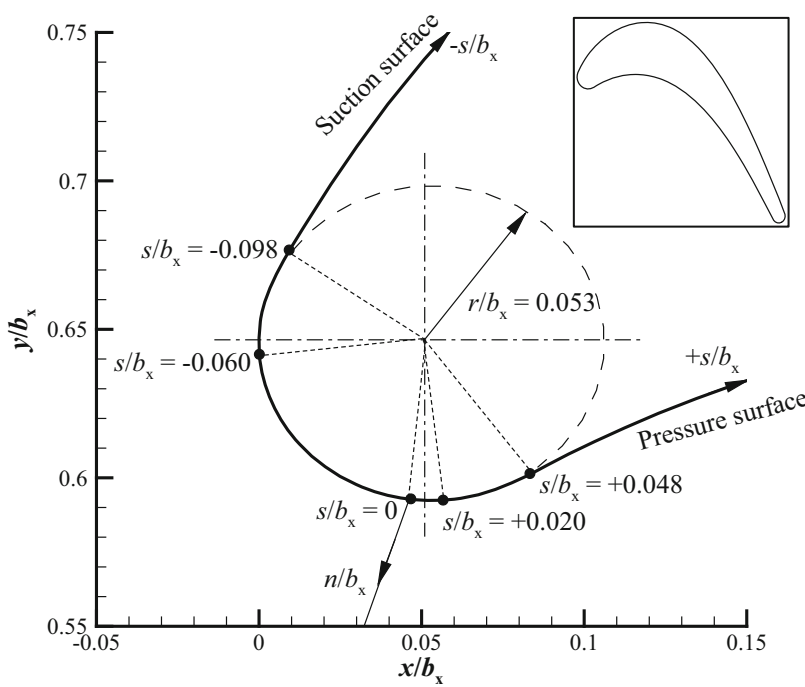

Figure 2. Details of the leading-edge geometry of the JT9D blade; the full blade is shown in the inset.

tunnel, with the blade scaled up to approximately ten times the actual size. This scaled geometry, with an axial chord length of $b_{x}=0.281 \mathrm{~m}$ and incidence angle of $44.7^{\circ}$, is employed in the present computations. The blade geometry, non-dimensionalized by $b_{x}$, is shown in figure 2 . It is convenient to define the leading-edge geometry by a bodyfitted coordinate system, with $s$ along the blade, and $n$ normal to it, and the origin situated at the stagnation point denoted by $\left(s / b_{x}, n / b_{x}\right)=(0,0)$. The leading-edge circle extends for $-0.098<s / b_{x}<0.048$; the stagnation region is about $-0.060<s / b_{x}<0.020$.

The domain for the computations consisted of one blade passage, and extended one axial chord length upstream of the blade leading edge and two axial chord lengths downstream of the trailing edge. A structured grid of O-grid topology around the blade was used to generate the computational grid within the flow domain. It was ensured that the grid was sufficiently fine near the blade surface. Since interest in the present study is primarily in the leading-edge region, a fairly large number of grid points were provided there. The grid over the rest of the blade also has a similar grid spacing to maintain grid uniformity. The computational domain is shown in figure $3 \mathrm{a}$ and the grid near the leading edge in figure $3 b$.

At the inlet of the computational domain, total and static pressure boundary conditions were imposed and at the outlet, the static pressure was specified. The outlet static pressure was set to obtain the required inlet velocity, $U_{\infty}=34 \mathrm{~m} / \mathrm{s}$, which corresponds to $R e=5.9 \times 10^{5}$, based on $U_{\infty}$ and $b_{x}$. The total temperature was specified at the inlet and outlet of the computational domain. The no-slip boundary condition and a constant heat flux, $q$, of $1310 \mathrm{~W} / \mathrm{m}^{2}$ were applied on the turbine aerofoil surface. The inlet turbulence intensity, $T u$, was set to $1 \%$. The values of $U_{\infty}$,

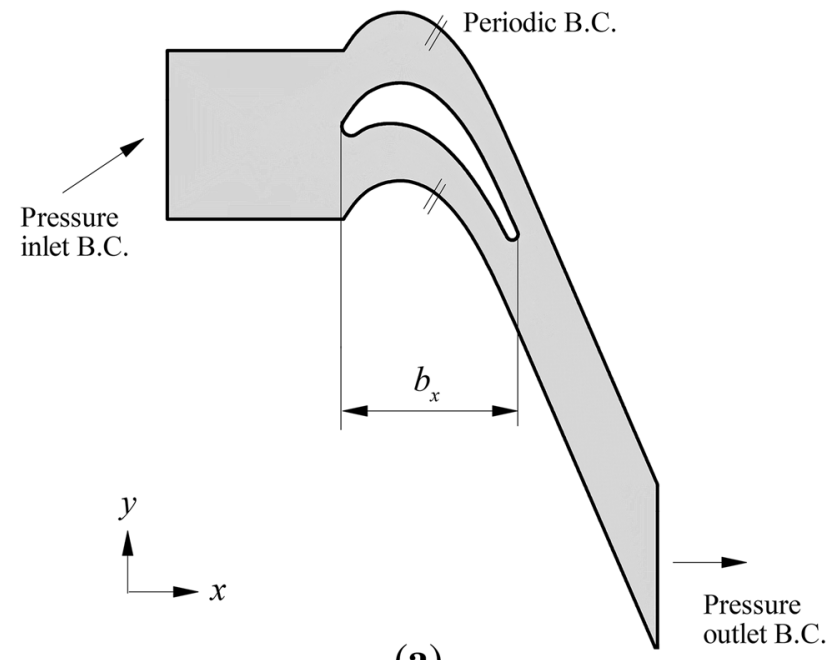

(a)

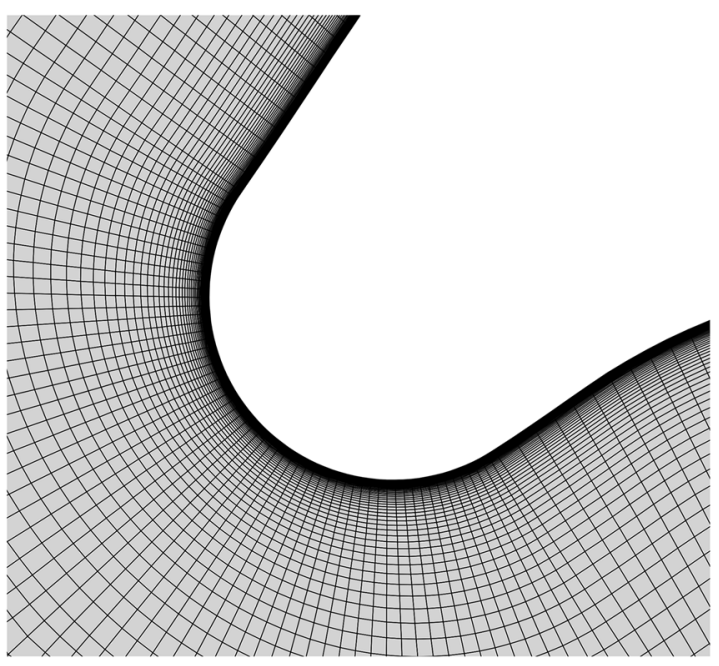

(b)

Figure 3. (a) Computational domain. (b) Grid near the leading edge.

$R e, q$ and $T u$ correspond to the experimental conditions. In the pitch-wise direction, periodic boundary condition was specified.

The Reynolds-averaged Navier-Stokes equations (RANS), listed here, were solved using the finite-volumemethod-based computational code Fluent.

$$
\frac{\partial \rho}{\partial t}+\frac{\partial}{\partial x_{i}}\left(\rho u_{i}\right)=0
$$

$$
\begin{aligned}
& \frac{\partial}{\partial t}\left(\rho u_{i}\right)+\frac{\partial}{\partial x_{j}}\left(\rho u_{i} u_{j}\right)= \\
& -\frac{\partial p}{\partial x_{i}}+\frac{\partial}{\partial x_{j}}\left[\mu\left(\frac{\partial u_{i}}{\partial x_{j}}+\frac{\partial u_{j}}{\partial x_{i}}-\frac{2}{3} \delta_{i j} \frac{\partial u_{l}}{\partial x_{l}}\right)\right]+\frac{\partial}{\partial x_{j}}\left(-\rho \overline{u_{i}^{\prime} u_{j}^{\prime}}\right)
\end{aligned}
$$




$$
\begin{aligned}
\frac{\partial}{\partial t}(\rho E)+\frac{\partial}{\partial x_{i}}\left[u_{i}(\rho E+p)\right]= & \frac{\partial}{\partial x_{j}}\left[k_{e f f} \frac{\partial T}{\partial x_{j}}+u_{i}\left(\tau_{i j}\right)_{e f f}\right] \\
& +S_{h}
\end{aligned}
$$

where $u_{i}$ and $u_{i}^{\prime}$ are, respectively, the mean and fluctuating velocity components, $\rho$ is the fluid density, $\mu$ is the viscosity, $p$ is the pressure and $k_{\text {eff }}$ is the effective thermal conductivity.

The shear-stress transport $k-\omega$ model [16] was used for turbulence modelling. The model equations are

$$
\begin{gathered}
\frac{\partial}{\partial t}(\rho k)+\frac{\partial}{\partial x_{i}}\left(\rho k u_{i}\right)=\frac{\partial}{\partial x_{j}}\left(\Gamma_{k} \frac{\partial k}{\partial x_{j}}\right)+G_{k}-Y_{k}+S_{k} \\
\frac{\partial}{\partial t}(\rho \omega)+\frac{\partial}{\partial x_{j}}\left(\rho \omega u_{j}\right)= \\
\frac{\partial}{\partial x_{j}}\left(\Gamma_{\omega} \frac{\partial \omega}{\partial x_{j}}\right)+G_{\omega}-Y_{\omega} \\
+D_{\omega}+S_{\omega}
\end{gathered}
$$

The $\gamma-R e_{\theta}$ transition model was employed for modelling the laminar-turbulent transition process; here, $\gamma$ is the intermittency and $R e_{\theta}$ is the Reynolds number based on the boundary layer momentum thickness. These equations are

$$
\begin{aligned}
& \frac{\partial}{\partial t}(\rho \gamma)+\frac{\partial}{\partial x_{i}}\left(\rho u_{j} \gamma\right)= P_{\gamma 1}-E_{\gamma 1}+P_{\gamma 2}-E_{\gamma 2} \\
&+ \frac{\partial}{\partial x_{j}}\left[\left(\mu+\frac{\mu_{t}}{\sigma_{\gamma}}\right) \frac{\partial \gamma}{\partial x_{j}}\right] \\
& \frac{\partial}{\partial t}\left(\rho \operatorname{Re}_{\theta t}\right)+\frac{\partial}{\partial x_{i}}\left(\rho u_{j} \operatorname{Re}_{\theta t}\right)= P_{\theta t} \\
&+\frac{\partial}{\partial x_{j}}\left[\sigma_{\theta t}\left(\mu+\mu_{t}\right) \frac{\partial \operatorname{Re}_{\theta t}}{\partial x_{j}}\right]
\end{aligned}
$$

The development of the $\gamma-R e_{\theta}$ transition model is documented in Menter et al [17], and its successful application to several turbomachinery flow cases in Langtry et al [18]. Further details of the models in Eqs. (13)-(16) can be found in [16] and [17]. The application of the $\gamma-R e_{\theta}$ model demands a near-wall $y^{+}$value of $<1$ and in the present computations, near-wall $y^{+} \sim 0.6$ was maintained. The spatial discretization of the RANS equations (10)-(12) was performed by a formally second-order accurate numerical scheme. The SIMPLE algorithm was employed for pressure-velocity coupling. The calculations were carried out in double-precision arithmetic. The convergence of the residuals of the various conserved variables was less than $10^{-6}$.

The number of grid points for the computations was chosen from a systematic grid independence study. This study was done for $R e=5.9 \times 10^{5}$ and the afore-mentioned conditions with 39,013 (coarse grid, with 42 grid

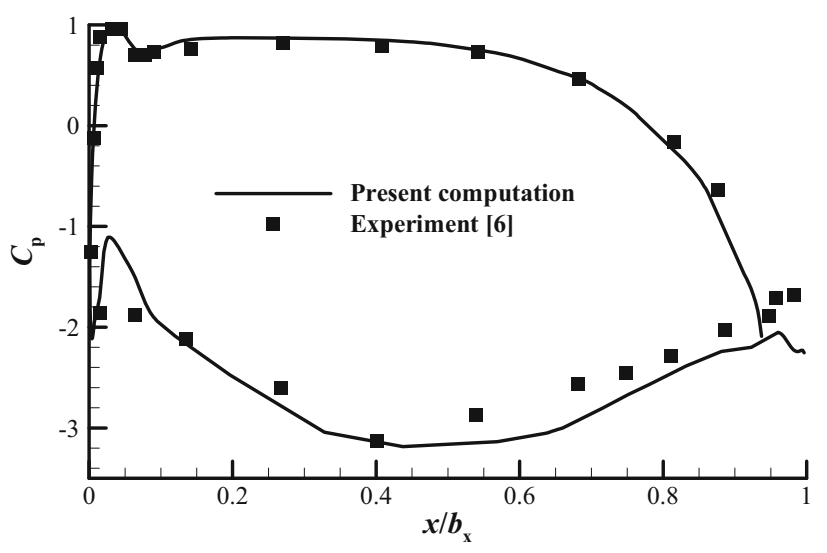

Figure 4. $C_{p}$ distribution over the turbine blade; $R e=5.9 \times 10^{5}$, $T u=1 \%$.

points at the leading edge), 88,337 (medium, 63) and 193,440 (fine, 95) grid points. The $C_{f}, C_{p}$ and $S t$ distributions over the blade, and particularly near the leading edge, were plotted (not shown here for the sake of brevity) for the results from these three grids. The results were found to be convincingly grid independent. Further, to formally quantify the discretization error, the Grid Convergence Index (GCI) [19] was calculated for $L / b_{x}$, evaluated from $C_{f}$ distribution (see section 4.1 for details). The numerical uncertainty in the calculation of $L / b_{x}$ in terms of the discretization error was $4.50 \%$ and $3.12 \%$ for the medium and fine grids, respectively. Since the medium grid had a reasonably low value of discretization error it was chosen for all subsequent computations. Later, the computational grid for different leading-edge geometries was constructed with similar grid spacing as with the medium grid here.

The computed $C_{p}$ distribution over the turbine blade is compared to the experimental data of [6] in figure 4 . The agreement is good, indicating a validation of the present computational procedure. A deviation in $C_{p}$ is seen after the mid-chord till the trailing edge on the suction side of the blade with a maximum deviation of 0.47 occurring at $x / b_{x}=0.68$. It was reported in [6] that in the experimental set-up, the presence of the end walls reduced the loading on the blades in this region due to the low aspect ratio of the cascade $(\operatorname{span} /$ axial chord $=0.99)$.

\section{Results and discussion}

\subsection{Leading-edge stagnation region}

In this section we shall take a closer look at the skin friction, pressure and heat transfer distributions in the stagnation region. Firstly, the $C_{f}$ distribution is plotted in figure 5 . The experimental $C_{f}$ measured by oil-film interferometry technique in [6] represents several hundreds of measurements from $15 \%$ to $60 \%$ of the blade span, which is a substantial portion of the blade span, in figure 5. It is 


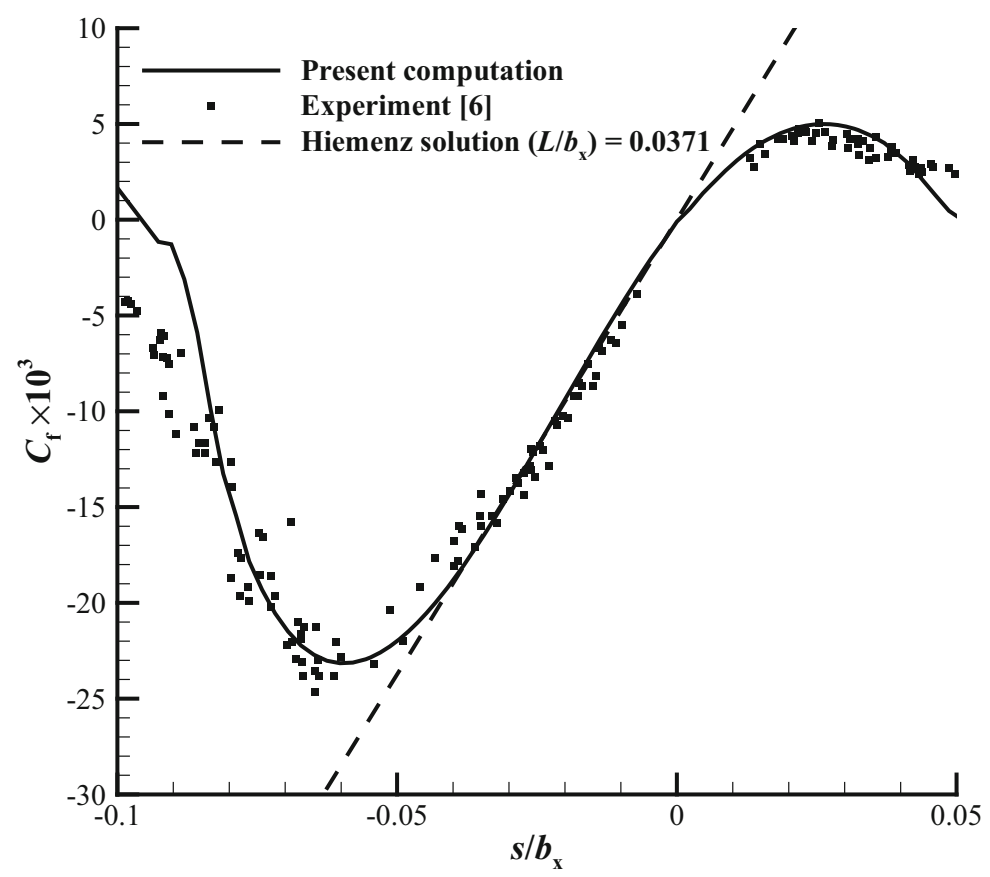

Figure 5. $C_{f}$ distribution in the stagnation region; $R e=5.9 \times 10^{5}, T u=1 \%$.

apparent that the $C_{f}$ distribution is linear in the stagnation region as seen from both the computational and experimental results. The region where the $C_{f}$ distribution is linear is reckoned as the stagnation region, i.e., $-0.06<s / b_{x-}$ $<+0.02$, which is about $55 \%$ of the aerofoil leading-edge circle. The extent of the linear region is more on the suction side than on the pressure side. Now, the slope of the $C_{f}$ curve at $s / b_{x}=0$ can be determined to evaluate $L / b_{x}$, and the Hiemenz flow solution as in Eq. (2) can then be used to describe the stagnation region. The value of $L / b_{x}$ evaluated

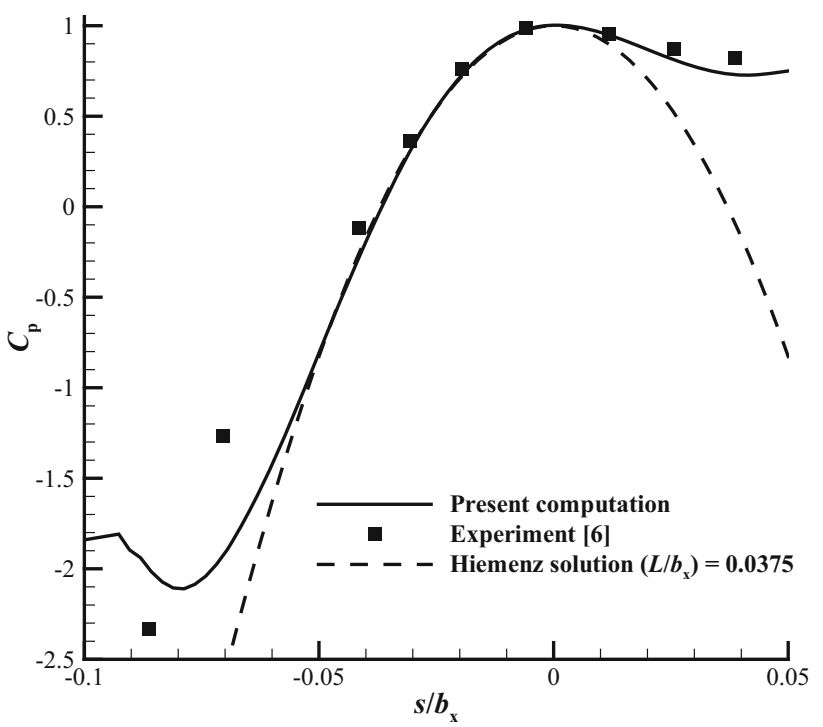

Figure 6. $C_{p}$ distribution in the stagnation region; $\operatorname{Re}=5.9 \times 10^{5}, \mathrm{Tu}=1 \%$. from the present computations was 0.0371 ; this value from the experiments of [6] was 0.0380 , and 0.0500 from their computations.

The $C_{p}$ distribution is plotted in figure 6, and is clearly parabolic in the stagnation region. The $C_{p}$ distribution can also be used to evaluate $L / b_{x}$ from Eq. (3). The value of $L / b_{x}$ thus obtained is 0.0375 . It is to be noted that this value is very close to that evaluated using the $C_{f}$ distribution. Thus the stagnation region can be characterized by the Hiemenz flow solution in terms of $L / b_{x}$, evaluated from either $C_{f}$ or $C_{p}$. In the present paper we have used $L / b_{x}$ evaluated from $C_{f}$, since these data were readily available from our computations, and also the $C_{f}$ distribution is rather relatively sensitive to changes in $R e$ and $T u$ than $C_{p}$ distribution. However, $L / b_{x}$ can be evaluated from $C_{p}$ as well as it is rather straightforward to measure pressure distribution in an experimental set-up without the need for elaborate instrumentation. Alternatively, a reasonably accurate estimation of pressure distribution can be obtained from computations even with a relatively coarse grid. It may be mentioned here that the values of $L / b_{x}$ evaluated from $C_{p}$ and $C_{f}$ are quite close, with the largest difference seen for the lowest values of $R e$ and $T u$ in the present study, and should not be a cause for major concern.

The St distribution in the stagnation region is shown in figure 7. The experiments of [15] for heat transfer measurements were conducted at a slightly lower $R e=5.5 \times 10^{5}$. We had also performed computations at this $R e$ to compare with the experimental data. It can be seen that $S t$ is not constant along $s / b_{x}$ as indicated by the experimental and two computational results. The present 


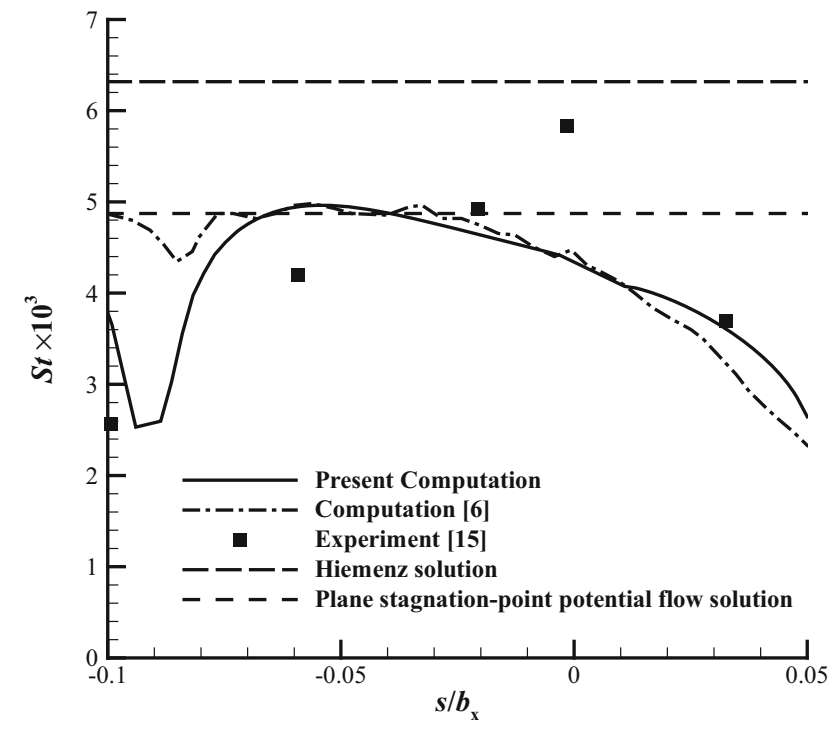

Figure 7. St distribution in the stagnation region. $R e=5.5 \times 10^{5}, T u=1 \%, q=1310 \mathrm{~W} / \mathrm{m}^{2}$.

computations qualitatively resemble and are close to the computations of [6]. The measured $S t$ value at the stagnation point lies within the values given by Eqs. (4) and (7).

It was demonstrated that a single parameter $L / b_{x}$ can be used to describe the aerodynamics and heat transfer at the stagnation region of a turbine blade. Once $L / b_{x}$ is evaluated it can be used to predict the bounds on $S t$ at the stagnation point through Eqs. (4) and (7). We will further explore the utility of $L / b_{x}$, and of Eqs. (4) and (7) in the next section.

\subsection{Variation of scaling parameter and heat transfer}

In the previous section we saw how $L / b_{x}$ describes the aerodynamics and heat transfer at the stagnation region of a turbine blade. The results were presented for $R e=5.9 \times 10^{5}$, and $T u=1 \%$. The turbine blades, particularly the nozzle guide vanes, are subjected to very high turbulence levels due to intense mixing in the combustor. However, the turbulence intensity for an operating combustor is generally not available [3]. It is commonly taken that $T u$ can be up to $20 \%-25 \%$ [1]. For example, van Fossen and Bunker [20] measured average turbulence intensity as high as $31.6 \%$ at the exit of a dual annular combustor segment similar to that used on a commercial high-bypass turbofan engine, with the test rig operating in cold flow mode. In the present section we study the aerodynamics and heat transfer at the stagnation region for Re varying from $1 \times 10^{5}$ to $5.9 \times 10^{5}$, and $T u$ ranging from $0.1 \%$ to $20 \%$. In particular, we are interested in evaluating $L / b_{x}$ for these conditions.

The values of $L / b_{x}$ for different $R e$ and $T u$ are plotted in figure 8. A systematic dependence of $L / b_{x}$ on both of these parameters is observed. At a given $R e$, for varying $T u, L / b_{x}$ decreases as the slope of the $C_{f}$ curve increases. Also, at a

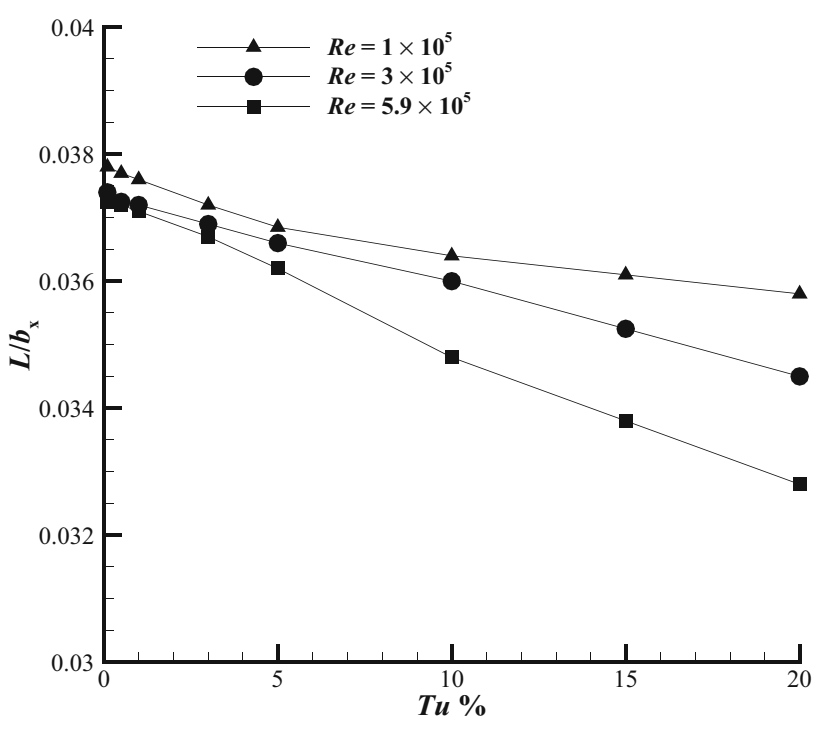

Figure 8. Variation of $L / b_{x}$ with $T u$ for different $R e$.

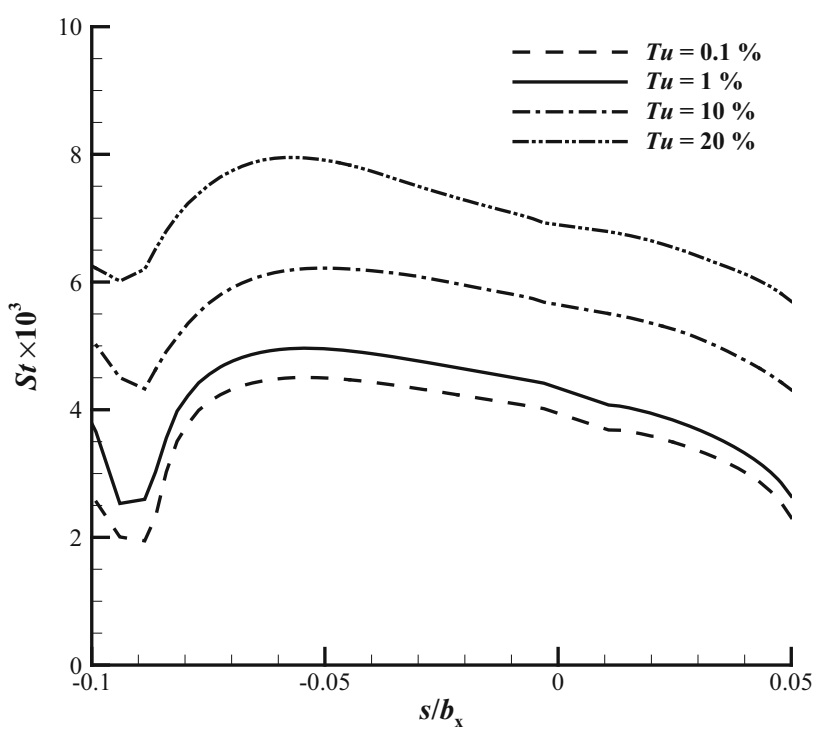

Figure 9. St distribution in the stagnation region for different values of $T u ; R e=5.9 \times 10^{5} ; q=1310 \mathrm{~W} / \mathrm{m}^{2}$.

given $T u$, as $R e$ increases the $C_{f}$ distribution in the leadingedge region becomes more flatter, resulting in lower values of $L / b_{x}$. Plots like figure 8 are useful in evaluating the scaling parameter for the range of flow parameters involved.

The $S t$ distribution in the stagnation region is shown in figure 9 for $R e=5.9 \times 10^{5}$ and different values of $T u$. A substantial increase in $S t$ is seen with increasing $T u$. It is well recognized that freestream turbulence augments the rate of heat transfer in flows with large mean strain rates. The rapid divergence of streamlines near the stagnation region causes large strain of the mean flow. Further, the vortical disturbances in the oncoming stream are amplified 


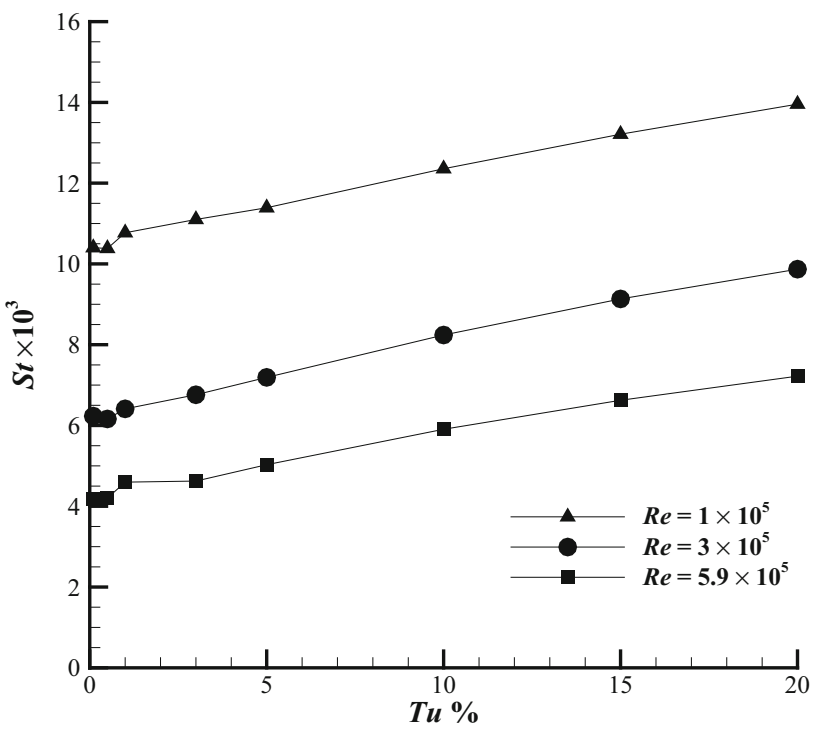

Figure 10. St values at the stagnation point for different $R e$ and Tu.

near the stagnation region, leading to enhanced heat transfer (see, for example, the recent studies in [21, 22] and the references therein). Our use of the scaling parameter $L / b_{x}$ here is equivalent to the mean strain rate.

It may be noted that the velocity near the stagnation region varies as $u=a x$. In general, the constant $a$ is proportional to the freestream velocity, $U_{\infty}$, and a characteristic length scale, $\lambda$, and is defined as follows:

$$
a=\alpha \frac{U_{\infty}}{\lambda}
$$

where the constant of proportionality $\alpha$ is called the acceleration coefficient, and depends on the shape of the body; $\alpha$ was implicit in our earlier definition of $a$.

For flow over a circular cylinder, potential flow theory yields $\alpha=4$, whereas in viscous flows, to first order, a typical value of $\alpha=3.6314$ is used. However, in general, $\alpha$ depends on $R e, T u$ and blockage. The values of $\alpha$ evaluated from the present computations show a systematic variation with $R e$ and $T u$. For example, $\alpha$ varies from 2.804 to 2.961 with $T u$ for $R e=1 \times 10^{5}$, and from 2.849 to 3.232 for $R e=5.9 \times 10^{5}$. It may also be mentioned here that from the present computations we observe that at given $T u$ an increase in $R e$ leads to lower values of $S t$ in the stagnation region. The $S t$ values at the stagnation point for the range of $R e$ and $T u$ considered in the present study are plotted in figure 10. Substantial heat transfer augmentation is seen at higher values of $T u$; for example, at $R e=5.9 \times 10^{5}$ and $T u=20 \%$, heat transfer augmentation in terms of $\left(S t-S t_{0}\right) / S t_{0}$ is about $73 \%$, where $S t_{0}$ is taken at the lowest $\mathrm{Tu}$. The recent experiments of Kingery and Ames [23] also show significant heat transfer augmentation in the stagnation region with increasing $T u$.

Now, having obtained $L / b_{x}$ and $S t$ for a range of $R e$ and $T u$, it is appropriate to check the usefulness of Eq. (8) or (9). The heat transfer data from the present computations and those published are plotted in figure 11. The stagnation-point heat transfer results for a wide range of turbine geometries, $R e$ and $T u$ are bounded by the model in Eq. (8) or (9). Of course, there are a few outliers, particularly at very low and very high $R e$ and $T u$. Some data points fall below the heat transfer values given by the Hiemenz flow. A few data points have heat transfer values beyond that predicted by the potential flow model. However, the model bounds well most of the data points from the present study

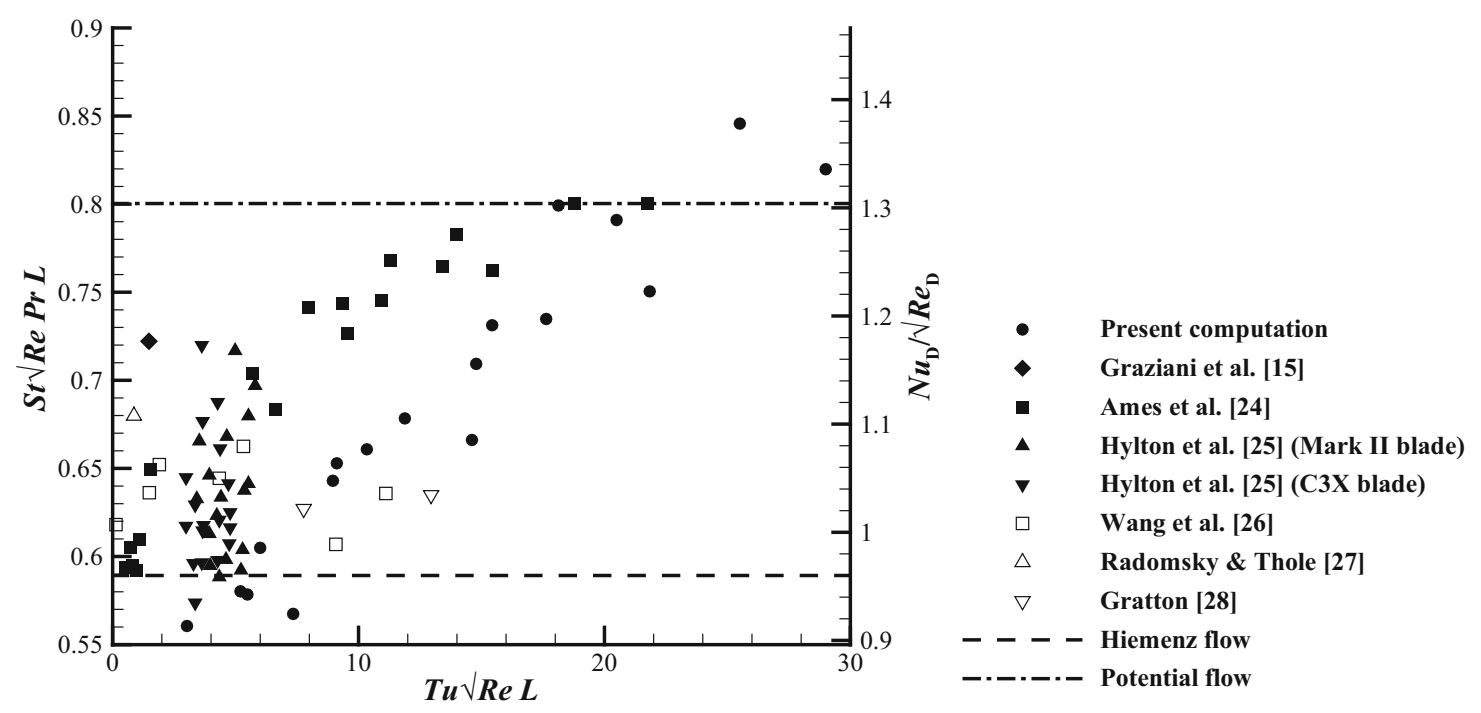

Figure 11. Heat transfer data at the leading-edge stagnation point from present computations and various sources. 


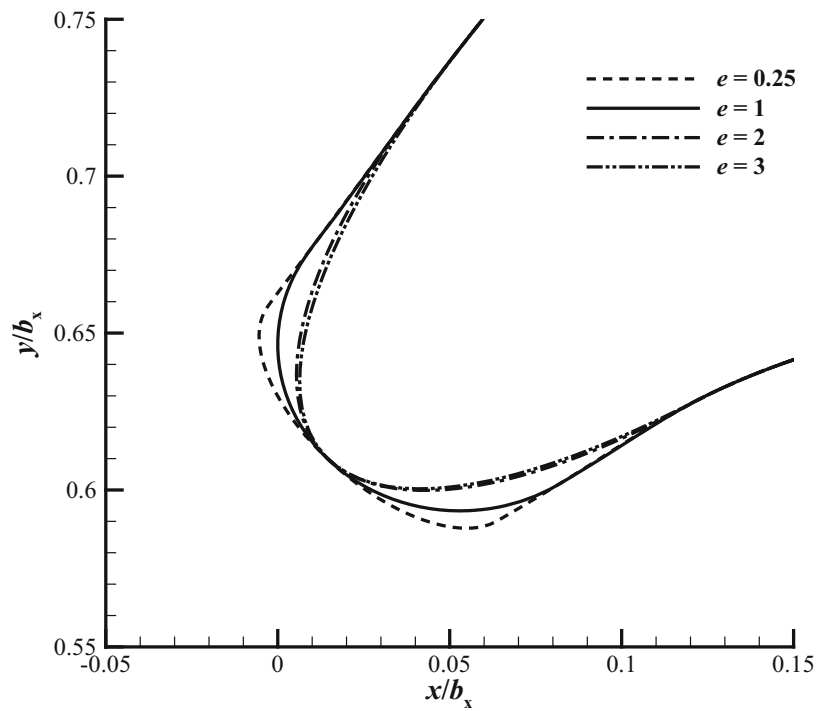

Figure 12. Elliptical leading-edge geometries.

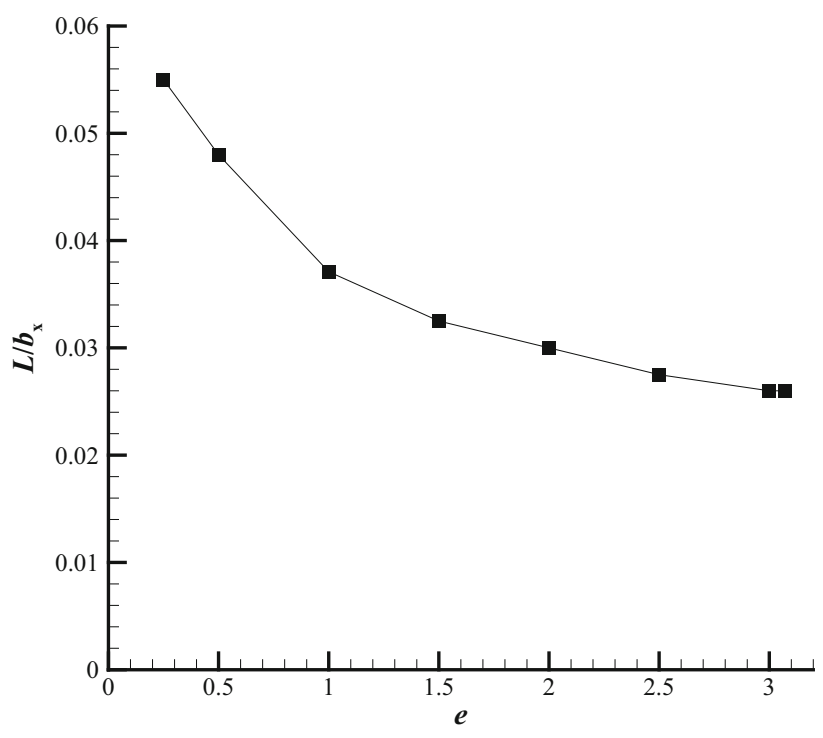

Figure 13. Variation of the scaling parameter with different leading-edge geometries.

and that available in the literature. Thus, once $L / b_{x}$ is known, Eq. (8) or (9) provides a bound for $S t$ values at the leading-edge stagnation point.

\subsection{Variation of scaling parameter and heat transfer with leading-edge geometry}

Now, having obtained $L / b_{x}$ and $S t$ for a given $R e$ and $T u$, it may be desired to reduce the heat transfer level in the stagnation region so that the cooling requirements are reduced. This can be done by carefully altering the value of $L / b_{x}$, which can be achieved by changing the leading-edge geometry. In the present section we discuss how the leading-edge geometry can be modified in a rational manner to obtain reduced heat transfer levels.

The JT9D blade geometry considered so far had a circular leading edge; see figure 2 . In the present study the circular leading edge is modified with an elliptical leading edge. However, care has to be taken while making such modifications. Firstly, the inlet blade angle, $\beta_{1}$, has to be maintained as in the original geometry since this is a specified blade design parameter. Otherwise, any change in $\beta_{1}$ due to modified leading edge may significantly alter the stagnation-point location and consequently the stagnation region aerodynamics and heat transfer. It may be noted that $\beta_{1}=43.99^{\circ}$ for the JT9D blade, and it was maintained for the newly generated elliptic leading-edge geometries. Secondly, the leading-edge geometry, circular or elliptic, has to smoothly blend with the rest of the blade geometry. The geometric discontinuity at the blend point leads to a 'spike' in the pressure distribution where there is a rapid flow acceleration, followed by a deceleration leading to boundary layer separation and subsequent reattachment, forming a separation bubble at the leading edge. Such a spike was observed in the experiments of Hodson [29], and in the more detailed leading-edge experiments of Walraevens and Cumpsty [30]. The leading-edge separation bubble can influence the boundary layer development over the rest of the blade. Some specific studies have been directed at smoothening this geometric discontinuity $[31,32]$. In the present paper we ensured tangency continuity between the leading edge and the main blade profile. In order to maintain these constraints the location of the blending point was allowed to move along the surface of the blade, necessitating small variations in the axial chord length of the blade, with the deviations being about less than $1 \%$ of $b_{x}$. However, the true chord length of the blade was kept unaltered.

The elliptical leading edge is defined by the ratio of its major to minor axis, $e$. The values of $e$ chosen in the present study are $0.25,0.50,1.00,1.50,2.00,2.50,3.00$ and 3.07. A few of the leading-edge geometries are shown in figure 12; $e=1.00$ corresponds to the circular leading edge; values of $e<1$ have blunt leading edges, and $e>1$ have sharper edges. The case $e=3.07$ is the sharpest ellipse that can be constructed without violating the constraints mentioned earlier. At the other extreme, the limiting case of a blunt leading edge is a square edge [33]. The effect of elliptical leading edge on stagnation region heat transfer has also been studied by Van Fossen et al [34].

We performed computations for the new blade geometries for $R e=5.9 \times 10^{5}, T u=1 \%, q=1310 \mathrm{~W} / \mathrm{m}^{2}$ and with the other conditions as before. The values of $L / b_{x}$ evaluated from the $C_{f}$ distribution are shown in figure 13 . We see that $L / b_{x}$ decreases with $e$. The stagnation-point $S t$ for the series of elliptical leading edges are shown in figure 14. The heat transfer is seen to decrease with blunter leading edges. The blunt leading edges have considerably 


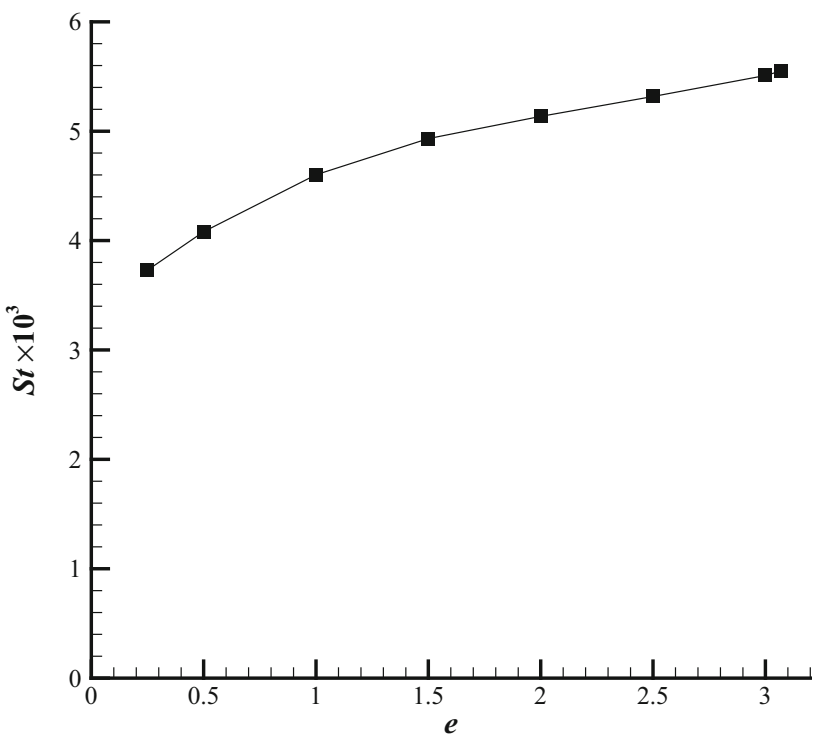

Figure 14. Stagnation-point St for different leading-edge geometries.

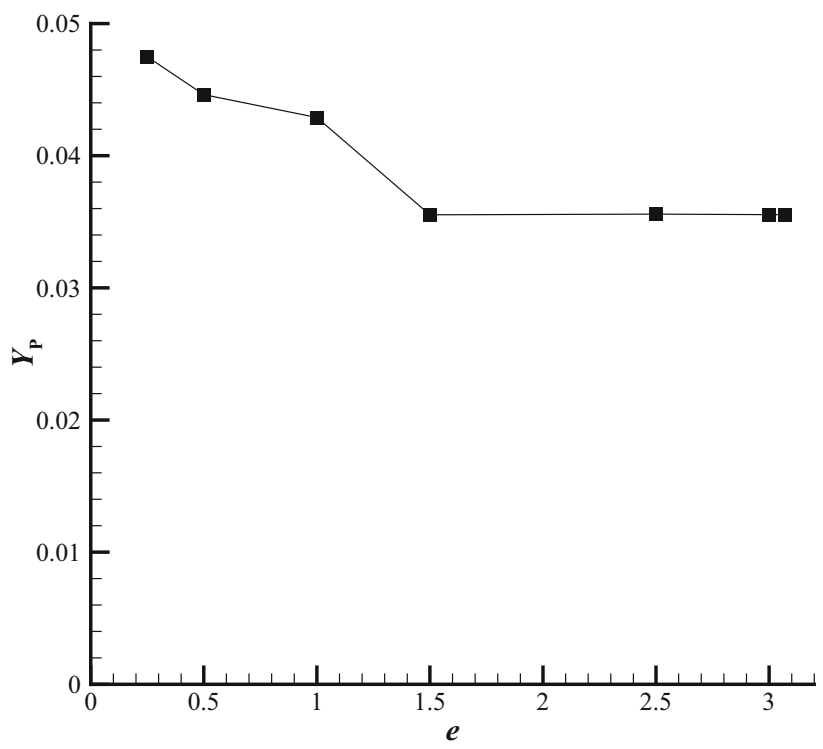

Figure 15. Loss coefficient, $Y_{P}$, for different leading-edge geometries.

small velocity gradients near the stagnation point, with $\alpha=1.648$ for $e=0.25$. It may be noted that for a square edge, $\alpha=(\pi / 2)[10,35]$. Thus, to reduce the heat transfer at the leading edge a blunter-leading-edge geometry can be chosen, which has larger $L / b_{x}$. This was indeed the suggestion made in [6], and the present results formally quantify this assertion.

The turbine blade stagnation region heat transfer and aerodynamic performance was discussed in the previous sections. It is also imperative to assess the overall aerodynamic performance of the turbine blade profile in terms of the blade profile-loss coefficient, $Y_{P}$, which is defined as follows:

$$
Y_{P}=\frac{p_{01}-p_{02}}{p_{02}-p_{2}}
$$

where $p_{01}$ and $p_{02}$ are the inlet and exit total pressure, respectively, and $p_{2}$ is the exit static pressure. The inlet and exit quantities were evaluated at $1 b_{x}$ ahead of the blade leading edge and $2 b_{x}$ behind the trailing edge, respectively. Further, the exit quantities are mass-weighted average values. This loss coefficient gives a measure of the total pressure loss in the turbine cascade. The $Y_{P}$ values for the different leading-edge geometries are plotted in figure 15 . The losses are higher for blunter leading edges. It may be necessary to compromise with the increased loss to accommodate for the lower heat transfer in the stagnation region.

Further, it is of interest to know the off-design aerodynamic performance characteristics of the turbine blades. We performed a series of computations with different leadingedge geometries at several incidences, $-20^{\circ} \leq i \leq 20^{\circ}$, $\left(R e=5.9 \times 10^{5}, T u=1 \%\right)$, and the results are plotted in figure 16. The off-design performance is typical of reaction-type turbine blading. The total pressure loss is nearly constant over a wide range of incidence, and the blade with circular leading edge performs better than ones with elliptical leading edges. The losses are lower with the sharpleading-edge blades. With blunt leading edges, the losses are higher and the incidence range of low-loss operation of the turbine is limited. The well-known Ainley-Mathieson correlation for estimating the profile loss is also plotted in figure 16 (adapted from [36]) for reference. As is often the case with many turbomachinery design processes, the design of a turbine involves careful and judicious

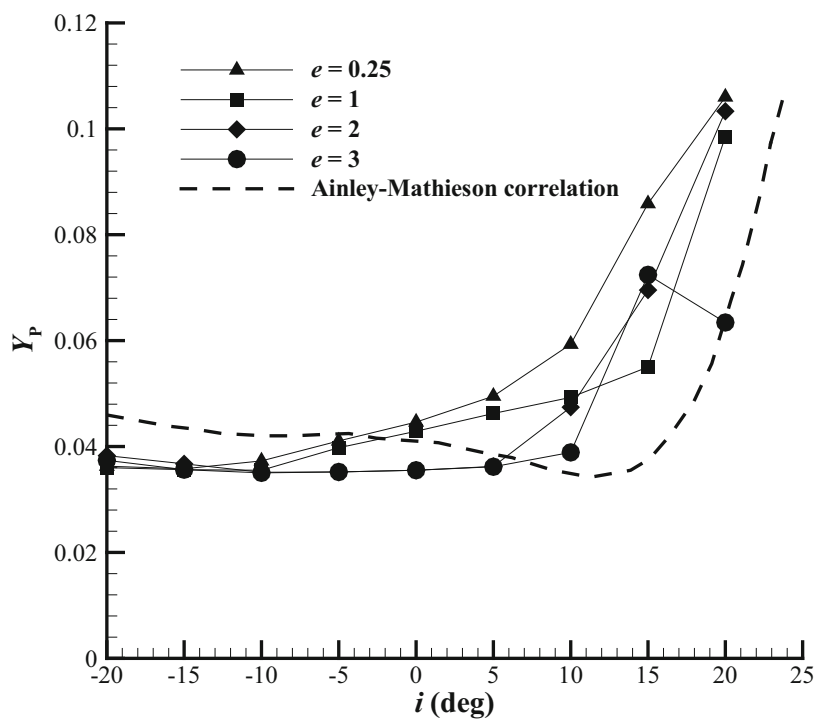

Figure 16. Off-design performance characteristics of turbine profiles with different leading-edge geometries. 
selection of design parameters to meet several conflicting requirements.

\section{Summary and conclusion}

The leading-edge stagnation region of uncooled turbine aerofoils was modelled based on the Hiemenz flow solution. It was shown, following Holley and Langston [6], that a single scaling parameter $L / b_{x}$ can be used to describe the flow field and heat transfer in the stagnation region. In the Hiemenz flow, skin friction distribution is linear in the stagnation region, pressure distribution is parabolic and heat transfer is uniform. The JT9D turbine blade has been used as an example to illustrate the application of Hiemenz flow solution to turbine aerofoils. The results were confirmed by RANS computations. It was also shown that the Hiemenz flow and plane stagnation-point potential flow heat transfer solutions provide lower and upper bounds, respectively, for heat transfer at the stagnation point. These solutions have strong theoretical basis, encouraging their use in developing analytical models for predicting stagnation region heat transfer in turbine aerofoils.

Further, computations were performed to evaluate the scaling parameter for different values of Reynolds numbers and freestream turbulence intensities. A systematic dependence of $L / b_{x}$ on both of these parameters was observed. Significant heat transfer augmentation in the stagnation region was found at values of high freestream turbulence. For example, at $R e=5.9 \times 10^{5}$ and $T u=20 \%$, heat transfer augmentation was about $73 \%$. For a wide range of $R e$ and $T u$, and turbine geometries, considered in the present study and data collected from published literature, a majority of the data points were well bounded by the model in Eq. (8) or (9). These equations can be useful in predicting the heat transfer at the stagnation point.

The leading-edge geometry of the JT9D turbine blade was modified with elliptical geometries. It was shown that $L / b_{x}$ can be carefully altered to reduce the heat transfer level in the stagnation region with a blunt elliptical leading edge. This geometry had lower values of heat transfer at the stagnation point compared with the original circular leading edge. However, its blade profile loss coefficient was higher. The results presented in this paper would be of use in evaluating the scaling parameter for a range of flow conditions, and in designing leading-edge geometries for reduced heat transfer in the turbine blade stagnation region.

\section{Nomenclature}

$a \quad$ velocity profile parameter $(1 / \mathrm{s})$

$b_{x} \quad$ axial chord length (m)

$C_{f} \quad$ skin friction coefficient

$C_{p} \quad$ pressure coefficient

$c_{p}$ specific heat at constant pressure $(\mathrm{J} / \mathrm{kg} \mathrm{K})$

$D \quad$ equivalent cylinder diameter (m) ratio of major to minor axis of ellipse

Frössling number

incidence angle (deg)

turbulence kinetic energy $\left(\mathrm{m}^{2} / \mathrm{s}^{2}\right)$

length scale (m)

nusselt number

pressure $(\mathrm{Pa})$

Prandtl number

heat flux $\left(\mathrm{W} / \mathrm{m}^{2}\right)$

Reynolds number

Reynolds number based on the boundary layer momentum thickness

$s, n \quad$ stream-wise and wall-normal coordinates, respectively (m)

St Stanton number

$T$ temperature (K)

$T u \quad$ turbulence intensity

$u, v$ velocity components along $x$ and $y$ directions, respectively $(\mathrm{m} / \mathrm{s})$

$U_{\infty} \quad$ freestream velocity $(\mathrm{m} / \mathrm{s})$

$x, y$ axial and pitch-wise coordinates, respectively (m)

$y^{+} \quad$ non-dimensional normal distance in wall units

$Y_{P} \quad$ blade profile-loss coefficient

\section{Greek symbols}

$\alpha \quad$ acceleration coefficient

$\alpha_{t}$ thermal diffusivity $\left(\mathrm{m}^{2} / \mathrm{s}\right)$

$\beta_{1} \quad$ inlet blade angle (deg)

$\gamma$ intermittency

$\delta^{*} \quad$ boundary layer displacement thickness (m)

$\lambda$ length scale $(\mathrm{m})$

$v \quad$ kinematic viscosity $\left(\mathrm{m}^{2} / \mathrm{s}\right)$

$\rho$ density $\left(\mathrm{kg} / \mathrm{m}^{3}\right)$

$\tau \quad$ shear stress $(\mathrm{Pa})$

$\omega$ specific dissipation rate $(1 / \mathrm{s})$

\section{Subscripts}

w wall

$\infty$ freestream condition

1 inlet

2 outlet

\section{References}

[1] Han J C, Dutta S and Ekkad S 2013 Gas turbine heat transfer and cooling technology, 2nd ed. Boca Raton: CRC Press

[2] Lakshminarayana B 1996 Fluid dynamics and heat transfer of turbomachinery. New York: John Wiley

[3] Dunn M G 2001 Convective heat transfer and aerodynamics in axial flow turbines. J. Turbomach. 123: 637-686

[4] Shih T I P and Yang V 2014 (Eds.) Turbine aerodynamics, heat transfer, materials and mechanics. Reston, VA: AIAA

[5] Frössling N 1958 Evaporation, heat transfer, and velocity distribution in two-dimensional and rotationally symmetrical laminar boundary-layer flow. NACA-TM-1432 
[6] Holley B M and Langston L S 2008 Analytical modeling of turbine cascade leading edge heat transfer using skin friction and pressure measurements. J. Turbomach. 130: 021001

[7] Schlichting H 1979 Boundary-layer theory, 7th ed. New York: McGraw-Hill

[8] Langston L S and Holley B M 2011 Turbine airfoil leadingedge stagnation aerodynamics and heat transfer - a review. Heat Trans. Res. 42: 3-23

[9] Goldstein S 1938 Modern developments in fluid dynamics, vol. II. Clarendon Press, Oxford

[10] White F M 2006 Viscous fluid flow, 3rd ed. New York: McGraw-Hill

[11] Kays W M, Crawford M E and Weigand B 2005 Convective heat and mass transfer, 4th ed. New York: McGraw-Hill

[12] Libby P A 1967 Heat and mass transfer at a general threedimensional stagnation point. AIAA J. 5: 507-517

[13] Davey A and Schoenfield D 1967 Three-dimensional flow near a two-dimensional stagnation point. J. Fluid Mech. 28: 149-151

[14] Langston L S, Nice M L and Hooper R M 1977 Threedimensional flow within a turbine cascade passage. J. Eng. Power 99: 21-28

[15] Graziani R A, Blair M F, Taylor J R and Mayle R E 1980 An experimental study of endwall and airfoil surface heat transfer in a large scale turbine cascade. J. Eng. Power 102: 257-267

[16] Menter F R 1994 Two-equation eddy-viscosity turbulence models for engineering applications. AIAA J. 32: 1598-1605

[17] Menter F R, Langtry R B, Likki S R, Suzen Y B, Huang P G and Volker S 2006 A correlation-based transition model using local variables - part I: model formulation. J. Turbomach. 128: 413-422

[18] Langtry R B, Menter F R, Likki S R, Suzen Y B, Huang P G and Volker S 2006 A correlation-based transition model using local variables - part II: test cases and industrial applications. J. Turbomach. 128: 423-434

[19] Celik I B, Ghia U, Roache P J, Freitas C J, Coleman H and Raad P E 2008 Procedure for estimation of uncertainty due to discretization in CFD applications. J. Fluids Eng. 130: 078001

[20] van Fossen G J and Bunker R S 2002 Augmentation of stagnation region heat transfer due to turbulence from an advanced dual-annular combustor. ASME Paper No. GT-2002-30184

[21] Xiong Z and Lele S K 2007 Stagnation-point flow under freestream turbulence. J. Fluid Mech. 590: 1-33

[22] Gifford A R, Diller T E and Vlachos P P 2010 The physical mechanism of heat transfer augmentation in stagnating flows subject to freestream turbulence. J. Heat Trans. 133: 021901
[23] Kingery J E and Ames F E 2016 Stagnation region heat transfer augmentation at very high turbulence levels. $J$. Turbomach. 138: 081005

[24] Ames F E, Wang C and Barbot P A 2003 Measurement and prediction of the influence of catalytic and dry low NOx combustor turbulence on vane surface heat transfer. J. Turbomach. 125: 221-231

[25] Hylton L D, Mihlec M S, Turner E R, Nealy D A and York R E 1983 Analytical and experimental evaluation of the heat transfer distribution over the surfaces of turbine vanes. NASA CR 168015

[26] Wang H P, Goldstein R J and Olson S J 1999 Effect of high free-stream turbulence with large length scale on blade heat/mass transfer. J. Turbomach. 121: 217-224

[27] Randomsky R W and Thole K A 2000 Flowfield measurements for a highly turbulent flow in a stator vane passage. $J$. Turbomach. 122: 255-262

[28] Gratton A R 2004 Measurements and predictions of heat transfer for a first vane design. MS Thesis, Virginia Polytechnic Institute and State University

[29] Hodson H P 1985 Boundary-layer transition and separation near the leading edge of a high-speed turbine blade. J. Eng. Gas Turbine Power 107: 127-134

[30] Walraevens R E and Cumpsty N A 1995 Leading edge separation bubbles on turbomachine blades. J. Turbomach. 117: $115-125$

[31] Hamakhan I A and Korakianitis T 2010 Aerodynamic performance effects of leading-edge geometry in gas-turbine blades. Appl. Energy 87: 1591-1601

[32] Zhang W, Zou Z and Ye J 2012 Leading-edge redesign of a turbomachinery blade and its effect on aerodynamic performance. Appl. Energy 93: 655-667

[33] Smith L H 1995 Discussion to Walraevens R E and Cumpsty $\mathrm{N}$ A, Leading edge separation bubbles on turbomachine blades. J. Turbomach. 117: 125

[34] Van Fossen G J, Simoneau R J and Ching C Y 1995 Influence of turbulence parameters, Reynolds number, and body shape on stagnation-region heat transfer. J. Heat Trans. 117: 597-603

[35] Hubble D O, Vlachos P P and Diller T E 2013 The role of large-scale vortical structures in transient convective heat transfer augmentation. J. Fluid Mech. 718: 89-115

[36] Dixon S L and Hall C A 2014 Fluid mechanics and thermodynamics of turbomachinery, 7th ed. Elsevier, New Delhi 